\title{
DR. 1298
}

SAND80-0433

Unlimited Release UC-62

\section{MASTER}

\section{SCRAM: A Fast Computational Model for the Optical Performance of Point Focus Solar Central Receiver Systems}

Kenneth D. Bergeron, Clement J. Chiang

Prepared by Sandia Laboratories, Albuquerque; New Mexico 87185 and Livermore, California 94550 for the United States Department of Energy under Contract DE-AC04-76DP00789

Printed April 1980

\section{Sandia National Laboratories}




\section{DISCLAIMER}

This report was prepared as an account of work sponsored by an agency of the United States Government. Neither the United States Government nor any agency Thereof, nor any of their employees, makes any warranty, express or implied, or assumes any legal liability or responsibility for the accuracy, completeness, or usefulness of any information, apparatus, product, or process disclosed, or represents that its use would not infringe privately owned rights. Reference herein to any specific commercial product, process, or service by trade name, trademark, manufacturer, or otherwise does not necessarily constitute or imply its endorsement, recommendation, or favoring by the United States Government or any agency thereof. The views and opinions of authors expressed herein do not necessarily state or reflect those of the United States Government or any agency thereof. 


\section{DISCLAIMER}

Portions of this document may be illegible in electronic image products. Images are produced from the best available original document. 
Issued by Sandia National Laboratories, operated for the United States Department of Energy by Sandia Corporation.

\section{NOTICE}

This report was prepared as an account of work sponsored by the United States Government. Neither the United States nor the Department of Energy, nor any of their employees, nor any of their contractors, subcontractors, or their employees, makes any warranty, express or implied, or assumes any legal liability or responsibility for the accuracy, completeness or usefulness of any information, apparatus, product or process disclosed, or represents that its use would not infringe privately owned rights.

Available from

National Technical Information Service

U.S. Department of Commerce

5285 Port Roya1 Road

Springfield, VA 22161

Price: Printed Copy $\$ 5.50$; Microfiche $\$ 3.00$ 
Unlimited Release

SAND 80-0433

TID4500-R67-UC62

\title{
SCRAM: A Fast Computational Model for the Optical Performance of Point Focus \\ Solar Central Receiver Systems
}

\author{
by \\ Kenneth D. Bergeron \\ and \\ Clement $J$. Chiang \\ Systems Analysis \\ Division 4723 \\ Sandia Laboratories \\ A1buque rque, NM 87185
}

\begin{abstract}
ABSTRAC'
Because of the complexities of heliostat shadowing and blocking calculations, computational models for the optical performance of point focus central receiver (PFCR) systems tend to be too slow for many important applications, such as optimization studies based on performance with realistic weather data. In this paper, a mathematical approximation procedure, designated 3andia Contral Receiver Approximation Model (SCRAM) will be described. Rather than simulating the system components frou first principles, it relies on data generated by the DELSOL code of Dellin and Fish for the optical performance of PFCR systems, and abstracts a mathematical model using a stepwise regression procedure. The result is a computational procedure which allows the user to define the heliostat field boundaries and tower height arbitrarily, generating a model for optical field performance, including sharowing, blocking, cosine losses, and atmospheric attenuation, and which requires only a polynomial evaluatiut for each set of sun angles. $\Lambda$ comparisnn with DELSOL for three different fields on three representative days indicates that the rms error of the approximation is $1-3 \%$ and that the new code is $1,000-3,000$ times as fast as DELSOL. It is also shown that one reason that the accuracy in field performance predictions is higher than that of the generating function for the model is that much of the error in the generating function is due to an osclllatory hehavior associated with a moire' pattern in the optical response of the heliostat fleld.
\end{abstract}

This book was prepared as an accourn of work sponsored by an agency of the United States Government.

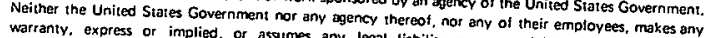
warranty, express or implied, or assumes any legal liability or responsibility for the accuracy.
complereness, or usefulness of any intormution.


commerciat product, process, or service by trade neme, irademark, Raference herein to any specific not necessarity constitute or imply its endorsement, trecommark, manulacturer, or otherwise, does States Government or any agency shereot. The views and opinions of authors expressed the United necessarily state or reflect those of the United. States Government or any agency thereof. 


\section{Acknowled gments}

Helpful conversations with $T$. Dellin and useful advice concerning the programming from L. L. Lukens are gratefully acknowledged. 


\section{CONTENTS}

$\begin{array}{lr}\text { I. Introduction } & \frac{\text { Page }}{7} \\ \text { II. Problem Definition } & 8 \\ \text { III. Generation of the SCRAM Model } & 12 \\ \text { IV. Moire Patterns in Optical Performance } & 15 \\ \text { V. Examples and Tests of the Approximation Model } & 18 \\ \text { VI. Conclusion } & 24 \\ \text { APPENDIX A - Heliostat Characteristics and Scaling } & 29 \\ \text { APPENDIX B - Generation of Field Model } & 33 \\ \text { APPENDIX C - Optional. Receiver Model } & 37 \\ \text { APPENDIX D - Computer Subroutines for Implementing the } & 43\end{array}$

\section{LIST OF TABLES}

Table

I. Energy Loss Mechanicsms for a PFCR system

II. Bacc Functions for Approximation Scheme

III. Coefficients Defining Approximation Model

\section{LIST OF FIGURES}

Figure

1. Field and sun angles for analysis

2. Local field efficiency as predicted by DELSOL 16

3. Blocking and shadowing losses 17

4. Logical structure of program using SCRAM 19

5. Power delivered to receiver area, (December 22) 21

6. Power delivered to receiver area (March 21) 22

7. Power delivered to receiver area (June 22) 23

8. Annual performance of a PFCR system based on TMY 25 weather data for Albuquerque, NM 


\section{Introduction}

Point focus central receiver (PFCR) systems, consisting of a field of individual heliostats which reflect and concentrate sunlight onto a heat exchanger at the top of a tower, are being seriously considered for large scale production of electricity and/or heat from solar energy. Though this "power tower" concept is simple, the mathematical modeling of optical performance is considerably more difficult than other sun-tracking systems (e.g. parabolic troughs or dishes). Primarily this is because the effects of tower blocking and sun shading depend on the precise orientation of each heliostat with respect to its neighbors, the tower, and the sun, so that complex computer codes are required to treat the problem realistically. Several such codes now exist, ${ }^{1,2,3}$ but they tend to require large computers and long running times. For some purposes (e.g. simulations in which hourly weather data is sampled to determine annual system performance at a particular location) the long running time of even the fastest of these codes $^{3}$ is prohibitive. The purpose of this paper is to describe a method for constructing an approximate mathematical model for the optical performance of a PFCR which requires very little computation time.

The approach is to make use of the existing simulation codes to generate a large amount of data which can be pictured as a surface in a manyparameter space. We then find a polynomial function which is a good approximation to this surface over the range of parameters of interest. The resulting model is called SCRAM (Sandia Central Receiver Approximation Mode1) and it is fast enough and accurate enough (compared to the original data base) that it can be used in simulations which sample weather and load variations and in system optimization studies which require thousands or hundreds of thousands of calls to the computational PFCR performance mode 1 in each run. An additional benefit is that SCRAM can be used for simple calculations on any computer regardless of size or speed.

It is clear that such an approximation model can be no more accurate or reliable than the simulation code which generates the data base. We will rely primarily on the DELSOL code developed for large applications 
by Dellin and Fish, ${ }^{3}$ and the resulting approximation model can be considered to be an adjunct to that code.

\section{Problem Definition}

There are a large number of parameters which affect the performance of a PFCR system. These include the position of the sun and its shape, the attenuation characteristics of the atmosphere, the laynut of the inirrors on the heliostats and of the heliostats on the field, the tower height, the receiver dimensions and thermal characteristics, the reflectivities of the mirrors and receiver, the tracking and focusing accuracies, and many more. For the sake of discussion, let us say there are $\mathrm{N}$ such parameters. The goal of our calculation is to find an approximate polynomial expression for the energy collected as a function of these $N$ parameters, but it is impractical to include all the parameters as independent variables in the polynomial. For one thing, the time and expense required to generate the data base via the large simulation code would be excessive (a reasonable sampling of the $\mathrm{N}$-dimensional space is required). For annther, the proress of searching for a good polynomial fit to the data would be very difficult. And finally, the resulting model would be too cumbersome for many of the purrposes envisioned.

Thus, it is necessary to select a subset of $n$ parameters to be treated as independent variables, and to choose values for the other $(N-n)$ parameters which will be held constant. This selection process is a matter of judgment and depends on the use for which the model is intended. For our model the following simplifications will be made:

a) A particular heliostat design will be chosen for the model. Any variation in the heliostat parameters requires the generation of a new data base and the construction of a new mode1.

b) Similarly, a particular heliostat layout pattern is chosen for the model. The boundaries of the field will be variable 
but the heliostat separations at each point in the field are not. Details of the parameters chosen for heliostat design and layout for the model which will be generated in Section III are given in Appendix A.

The efficiency, $n$, of a PFCR system is defined as the power absorbed by the receiver heat transfer fluid divided by the solar power incident on an area equal to the mirror area oriented normal to the sun's rays. We can write this as a product of the field efficiency and the receiver efficiency and break each of these up into terms associated with different power loss mechanisms as follows:

$$
\begin{gathered}
n=n_{\text {field }} \cdot n_{\text {receiver }} \\
n_{\text {field }}=n_{1} \cdot n_{2} \cdot n_{3} \cdot n_{4} \cdot n_{5} \\
n_{\text {receiver }}=n_{6} \cdot n_{7} \cdot n_{8} \cdot n_{9} \cdot n_{10}
\end{gathered}
$$

\begin{tabular}{|c|c|}
\hline Term & Loss Mechanism \\
\hline$n_{1}$ & Cosine--mirror is not normal to sun's rays \\
\hline$n_{2}$ & Shadowing--shadow of oue luliustat fallo on another \\
\hline$n_{3}$ & $\begin{array}{l}\text { Blocking--light reflected from one heliostat is intercepted by } \\
\text { another }\end{array}$ \\
\hline$n_{4}$ & Absorption--at mirror surface \\
\hline$n_{5}$ & Attenuation--in the air between heliostat and receiver \\
\hline \multicolumn{2}{|r|}{ 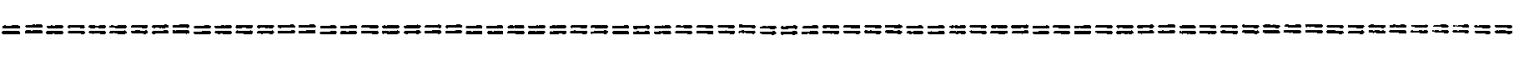 } \\
\hline$n_{6}$ & Spillage--reflected light misses receiver apcrture \\
\hline$n_{7}$ & Reflection--from receiver surface \\
\hline$n_{8}$ & Radiation--due to elevated temperature of receiver surface \\
\hline$n_{9}$ & Convection--loss to air adjacent to receiver \\
\hline$n_{10}$ & Conduction--luss to receiver eupport structure \\
\hline
\end{tabular}

Table I indicates the loss mechanism associated with each term.

Table I. 
In the present analysis, we will achieve an additional simplification by modeling only $\eta_{\text {field }}$. There are several reasons for this:

a) Substantial mathematical simplification is achieved.

b) The dominant losses are the field losses.

c) Thermal loss mechanisms $\left(n_{8}, n_{9}, n_{10}\right)$ are poorly understood in the relevant parameter regimes, and there are, at this time, no reliable models for these processes (particularly for convective 1os ses). 4

The intention is not to ignore receiver losses, but rather to separate the problem into two parts and deal only with that part which existing codes (e.g. DELSOL) treat well. Our model for $\eta_{\text {field }}$ can then be coupled with realistic models for the receiver and/or the load. For illustrative purposes, a simplified receiver model will be introduced in Section $V$. and described in Appendix C. All terms in $\eta_{\text {field }}$ scale geometrically with tower height, except $n_{5}$, which will be treated separately. This means that we can use the tower height, $h$, as the unit of length throughout the calculation until the final evaluation of total power incident on the receiver region.

We have thus reduced the problem to two key mathematical steps. First, we generate (using DELSOL) a set of data points describing the eurface

$$
n_{0}(r, \beta, \theta, \phi) \equiv n_{1} \cdot n_{2} \cdot n_{3} \cdot n_{4}
$$

which is the local field efficiency at each radius ( $r$ ) and azimuth ( $\beta$ ) in the field for a particular set of sun polar $(\theta)$ and azimuthal $(\phi)$ angles. (The tower is located at $r=0--$ see Figurp 1.) Second, we find a polynomial approximation for this surface.

$$
\eta_{p}(r, \beta, \Theta, \phi) \equiv \eta_{s}(r, \beta, \Theta, \phi)
$$






Figure 1. Field and sun angles for analysis 
With this we can calculate the field efficiency for any field boundaries:

$$
\eta_{f}(\theta, \phi)=c_{f}(\theta, \phi) / A_{m}
$$

where $A_{m}$ is the total mirror area (in $\mathrm{m}^{2}$ ) and

$$
C_{f}(\theta, \phi)=h^{2} \int_{\text {field }} \int_{n_{5}} \eta_{5}(r, h) \rho(r, \beta) \eta_{p}(r, \beta, \theta, \phi) r d r d \beta
$$

where $\rho(r, \beta)$ is the field mirror density (ratio of mirror area to land area). If $\mathrm{D}$ is the direct normal insolation (watt $/ \mathrm{m}^{2}$ ), theu llie puwer reflected from the field incident on the receiver area is simply

$$
P_{f}=C_{f} D
$$

The total power, $P$, is obtained by subtracting from $P_{f}$ the losses associated with the terms $n_{6}$ through $n_{10}$.

TTT. Genoration of the SCRAll ulude 1

Tliece are many ways to generate an approximate fit to a function of several variables. The procedure described below was chosen because of i,ts suitability to the behavior of $n_{s}$ and for easy implementation of the integration in Eq. (5). We first note that symmetry considerations reduce the number of independent variables to three: $r, \theta$, and $\xi=\phi-\beta$. We then assume

$$
n_{p}=\sum_{i, j, k} c_{1 j k} u_{1}(\theta) v_{j}(\xi) w_{k}(r)
$$

where $U, V$, and $W$ are the base functions for the approximation optinization. The indices $i, j, k$ will range from 1 to 4 and the choice of base functions is shown in Table II. We have made use of the symmetry of $n_{s}$ about $\xi=0$ by using only even functions of $\xi$ in the sum (7). (The odd functions $U_{5}$, $\mathrm{U}_{6}$, and $\mathrm{U}_{7}$ as defined in Table II will be used in subsequent calculations.) 
Table II.

\begin{tabular}{ccccc}
\hline Index & $U_{i}(\xi)$ & $U_{i+4}(\xi)$ & $v_{j}(\theta)$ & $W_{k}(r)$ \\
1 & 1 & $\sin \xi$ & 1 & $\mathrm{r}^{-1}$ \\
2 & $\cos (\xi)$ & $\sin (2 \xi)$ & $\cos \theta$ & 1 \\
3 & $\cos (2 \xi)$ & $\sin (3 \xi)$ & $\sin \theta$ & $\mathrm{r}$ \\
4 & $\cos (3 \xi)$ & - & $\cos \theta \sin \theta$ & $\mathrm{r}^{2}$ \\
\hline
\end{tabular}

There are 64 terms in the sum in Eq. (7). The goal is to find a set of coefficients $C_{i j k}$, most of which are zero, yet which give an acceptable fit to the surface $\eta_{s}$. For this we use a stepwise regression program developed at Kansas State University and Sandia Laboratories. ${ }^{5}$ One can think of the procedure as mapping $\eta_{s}$ onto the 64-dimensional hyperspace defined by the variables specified in Table II, and then finding the best fit (in the least squares sense) for any $M$-dimensional hyperplane as $M$ is sequentially increased from 1 to 2 to 3 , etc. It is generally found that Lliere is a point of diminishing returns around $M=10$, after which relatively little reduction in the root mean square (rms) error of the approximation occurs.

This procedure has been applied to data generated by DELSOL to construct a model for a particular heliostat and layout pattern (decalled parameters are given in Appendix A). Table III contains the coefficients $C_{i j k}$ for the resulting model. All coefficients not listed are zero. (It should be noted that this model is restricted in validity to the range $.4<r<8.0$ and its use beyond this range would be an extrapolation from the original DELSOL data.) The rms error of the approximation (compared to the original data base) is .041 , which corresponds to a relative error of $6.5 \%$. For reasons which we will discuss later, the relative error in the predictions for field performance will be considerably less than this error in local efficiency. 
Table III.

\begin{tabular}{cccc}
\hline$i$ & $j$ & $k$ & $c_{i j k}$ \\
\hline 1 & 1 & 1 & -.9260 \\
1 & 1 & 2 & .5466 \\
2 & 1 & 1 & .9343 \\
2 & 1 & 2 & .1114 \\
3 & 1 & 1 & .5656 \\
3 & 2 & 3 & .0824 \\
3 & $i$ & 2 & -.02308 \\
4 & 2 & 2 & .07426 \\
3 & 2 & 4 & -.005781 \\
\hline
\end{tabular}

The next step is to develop a procedure which will integrate the local efficiency $n_{p}$ over the field for some specified field boundacies. It is desirable that this integration be done without specifying $\theta$ and $\phi$ so that once a field has been set up, multiple calls to the performance model can be made which require only a polynomial evaluation, not a numerical integration. For this reason we rewrite Eq. (6) in the following way.

$$
C_{f}(\theta, \phi)=\sum_{\substack{i=1,4 \\ j=1,7}} x_{i j} v_{i}(\theta) U_{j}(\phi)
$$

where the coeficients $X_{i j}$ are sums of integrals over the field variablas, $r$ and $B$, and are independent of $A$ and $\phi$, Exprooions for Llet $X_{i j}$ and a derivation of $\mathrm{Eq}$. (8) are given in $\Lambda$ ppondix B. Once these coefficients have been evaluated for a particular field configuration, the optical performance of the field for any sun angles requires only the evaluation of the polynomial in Eq. (8), which requires very little computer tine. 
IV. Moire' Patterns in Optical Performance

Before the details of the procedure for implementing the analysis of the preceding section are given, it is relevant to point out an unusal characteristic of the optical properties of a PFCR system. In Figure 2 we have plotted the local heliostat field ef ficiency $\eta_{s}(r, \beta, \theta, \phi)$ (see Eq. (4)) vs. $\xi=\phi-\beta$ for a fixed $r$ and $\theta$, as predicted by DELSOL. Superimposed on the slow (long wavelength) variation, which we associate with cosine losses, is a short wavelength oscillation having 6 cycles from $0^{\circ}$ to $360^{\circ}$.

All of this variation can be found to reside in the product $n_{2} \cdot n_{3}$, due to heliostat shadowing and blocking. It can be better understood by referring to Figure 3 , where $\left(1-n_{2} n_{3}\right)$ is plotted as the dot density in a polar plot of $r$ and $\xi$ for a fixed $\theta$. (A large value of $\theta$, corresponding to a time near sunset, was chosen so that shadowing effects are emphasized.) Fig. 3 represents the actual visual appearance of the heliostat field at a particular moment in time, and what we see is a moirepattern, which typically results from the superposition of two patterns which are spatially periodic with approximately the same wavelength but phase shifts which result in dark and light bands (corresponding to alternating regions of destructive and constructive interference). In this case the two superimposed patterns are the heliostats and their shadows.

Each lobe of the moire- pattern corresponds to a different mode of shadowing. For example, the horizontal lobe corresponds to the shadowing of one heliostat by a neighbor in the same ring, while the one at $\xi=45^{\circ}$ is due to a shadow cast from one ring to another on a diagonal from the radius vector. (Since the azimuthal heliostat separation is constant with radius, while the radial separation increases with increasing radius, all the lobes except the horizontal one disappear beyond a certain radius. ${ }^{6}$ )

This behavior has important implications for an approximation procedure of the kind under consideration here. In order to follow the short wavelength variation, it would be necessary to include a large number of short wavelength base functions in the sum in Eq. (7); the four functions 


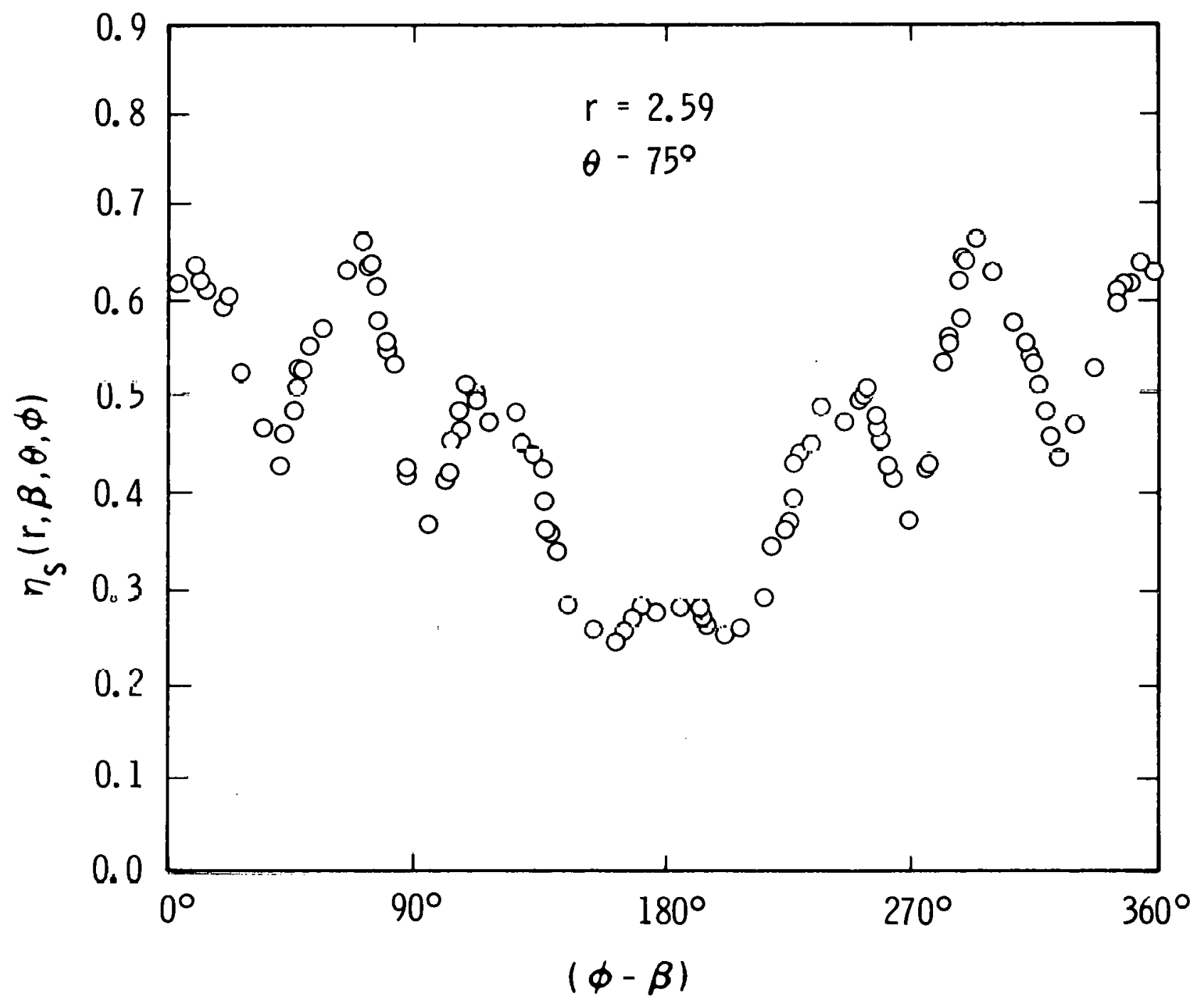

Figure 2. Local field efficiency as predicted by DELSOL, as a function of $(\phi-\beta)$ at a fixed radius in the field, and for a fixed zenith angle. 


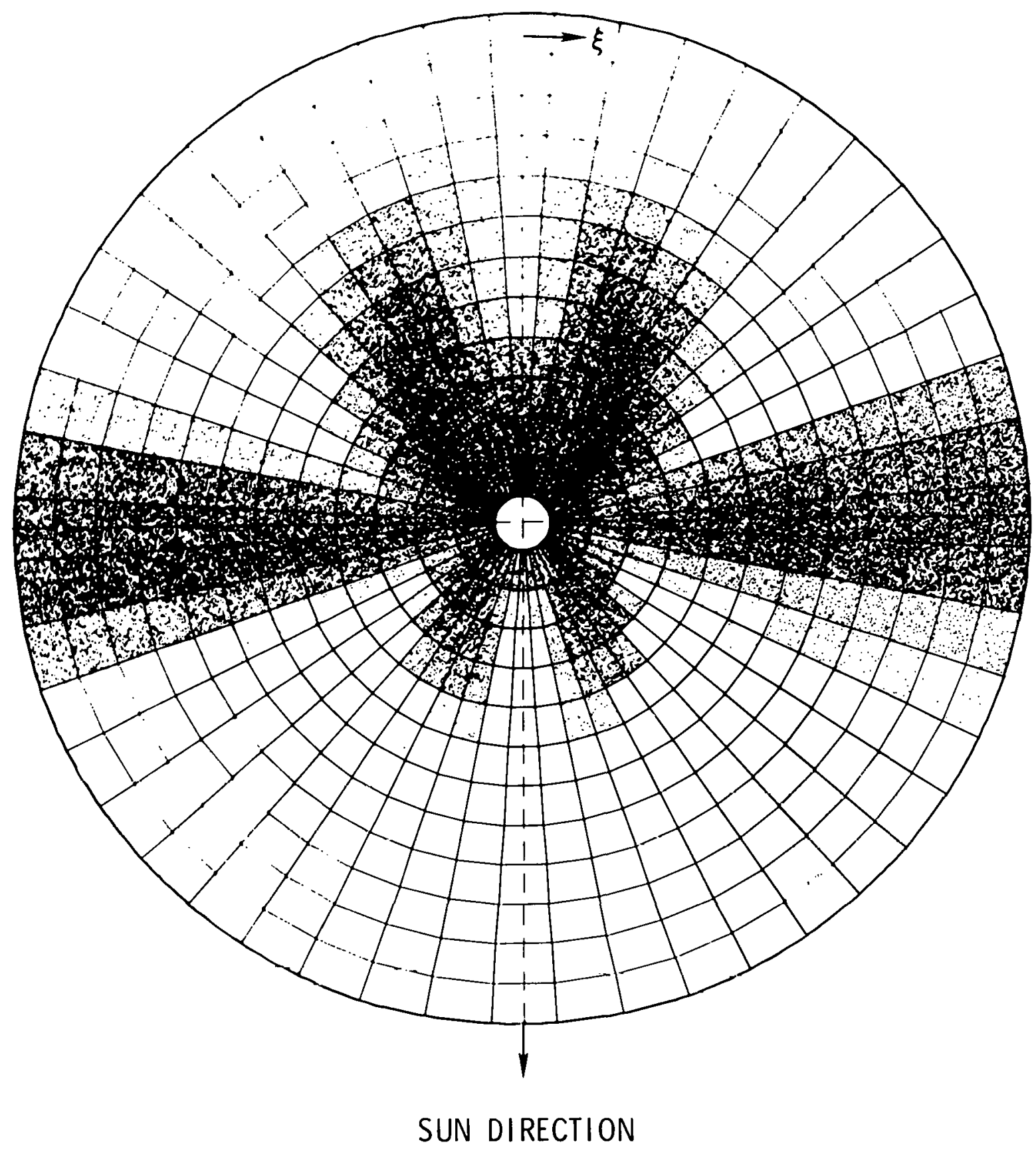

Figure 3. Blocking and shadowing losses plotted as the dot density on a polar plot of the field variables $(r, \beta)$. This moire pattern results from the alignment of the shadow pattern with the mirror pattern. 
$\mathrm{U}_{\mathbf{i}}(\xi)$ would not be nearly adequate. If this were done, the entire procedure would become considerably more complex and cumbersome. If it were not done, the approximating function would be a smoothed version of the curve shown in Figure 2. The short wavelength oscillation would then contribute significantly to the rms error of the approximation for $\eta_{S}$.

However, because this deviation is oscillatory, its contribution to the error in the approximation for the total field performance is expected to be considerably less than if it were due to random deviation. This is because in the integration over field angle the effect of a positive deviation is effectively cancelled by the negative deviation in the next halr." cycle of the oscillation. We will see in the next section that the relative erior in the approximation for field performance is considerably less than that for local efficiency.

\section{Examples and Tests of the Approximation Model}

There are numerous ways that the procedure described in Section III could be implemented to construct a fast performance model for PFCR systems. To demonstrate the use of the procedure and to test its accuracy, we have written a program which al1nws the specification of arbitraiy lleld hoindaries (within the limits of $.4<\mathrm{r}<8$ ) and which samples hourly weather data from the TMY tapes ${ }^{7}$ to determine annual performance characteristics of the field. The logical structure of the program is sliuwu lil Figure 4. All of the PFCR modeling functions arc contained in the subroutines FLDSET, DENS, and SCRAM so that they could he used unaltored for a number of different purposes with different calling programs. Appendix C contains a listing of these programs, (though it should be noted that for applications on systems other than the one at Sandia Laboratories the subroutines QNC3 and AVINT may have to be replaced by other numerical quadrature routines).

The philosophy behind our analysis is that it is not necessary to model receiver performance at the same time as field performance. It is assumed to be adequate for system design studies, for example, to optimize the field on the basis of field efficiency, and subsequently to optimize receiver 


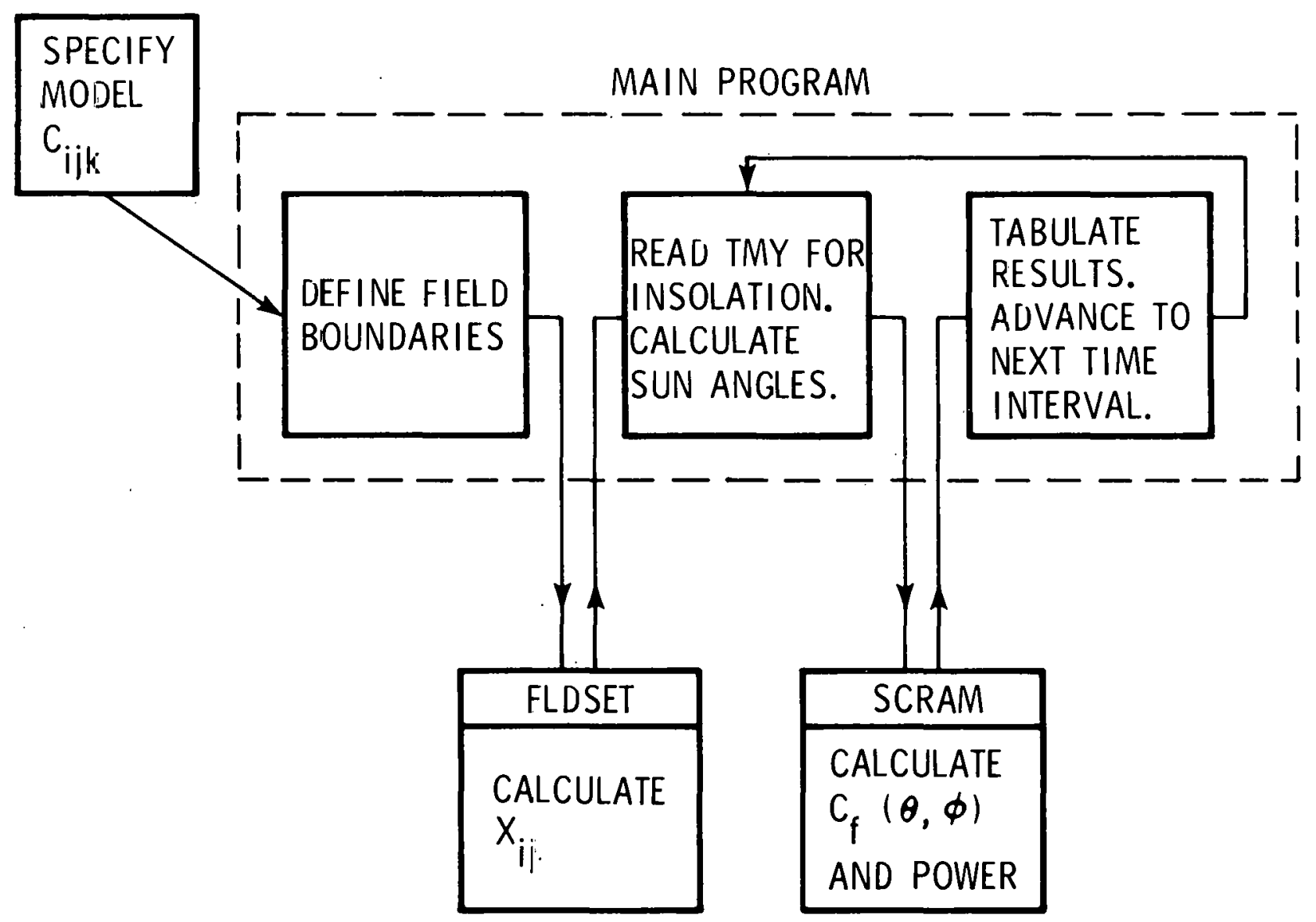

Figure 4. Logical structure of the program which uses the SCRAM model to predict annual perfirmance of PFCR systems for realistic weather data. 
design on the basis of the fixed field design. The reason for this effective decoupling is that the dominant cost of the PFCR is the heliostat field. To give an example of how a receiver model would be incorporated in this analysis, we have included a simple example in the program. Receiver losses are written as the sum of two terms: one proportional to the insolation (which includes $n_{6}$ and $n_{7}$ ) and the other a constant (including $n_{8}, n_{9}$, and $n_{10}$, which are fixed for a given receiver operating temperature). Details are presented in Appendix C.

We have tested the accuracy of our method by evaluating the performance of three different fields on three different days of the year, and comparing with the predictions of DELSOL for the same fields and days. A clear sky weather model was employed. The rasults are shown in Figures 1, 2, and 3. As can be seen, the approximation is very good over the entire range of parameters. In fact, it is a "better" approximation, in the least squares sense, than the original approximation for the local efficiency $n_{s}(r, \beta, \theta, \phi)$. We can see this by calculating the relative rms error, which we define as

$$
e=\left\{N^{-1} \sum_{i=1}^{N}\left(1-P_{s i} / P_{D i}\right)^{2}\right\}^{1 / 2}
$$

where $P_{s i}$ is the SCRAM prediction for power collected at the $i^{\prime}$ th time interval, and $\mathrm{P}_{\mathrm{Di}}$ is the corresponding DELSOL prediction.

As indicated in Figures 5-7, e is $3 \%$ or less for all cases considered, which should be compared with the $6.5 \%$ ertor characterizing the local fleld efficiency approximation (see Section III.). The reason for the reduction in the error is that not all of the deviation of $n_{p}$ from $n_{s}$ is random-a significant portion comes from the shadowing and blocking moire' pattern, as discussed in Section IV. The level of $3 \%$ error is probably more than adequate for most PFCR modeling requirements, since the uncertainty in many of the parameters used as input to DELSOL are greater. (For example, the variation in heliostat reflectivity due to accumulation of dust and dirt between washings will be considerably higher. ${ }^{8}$ ) 


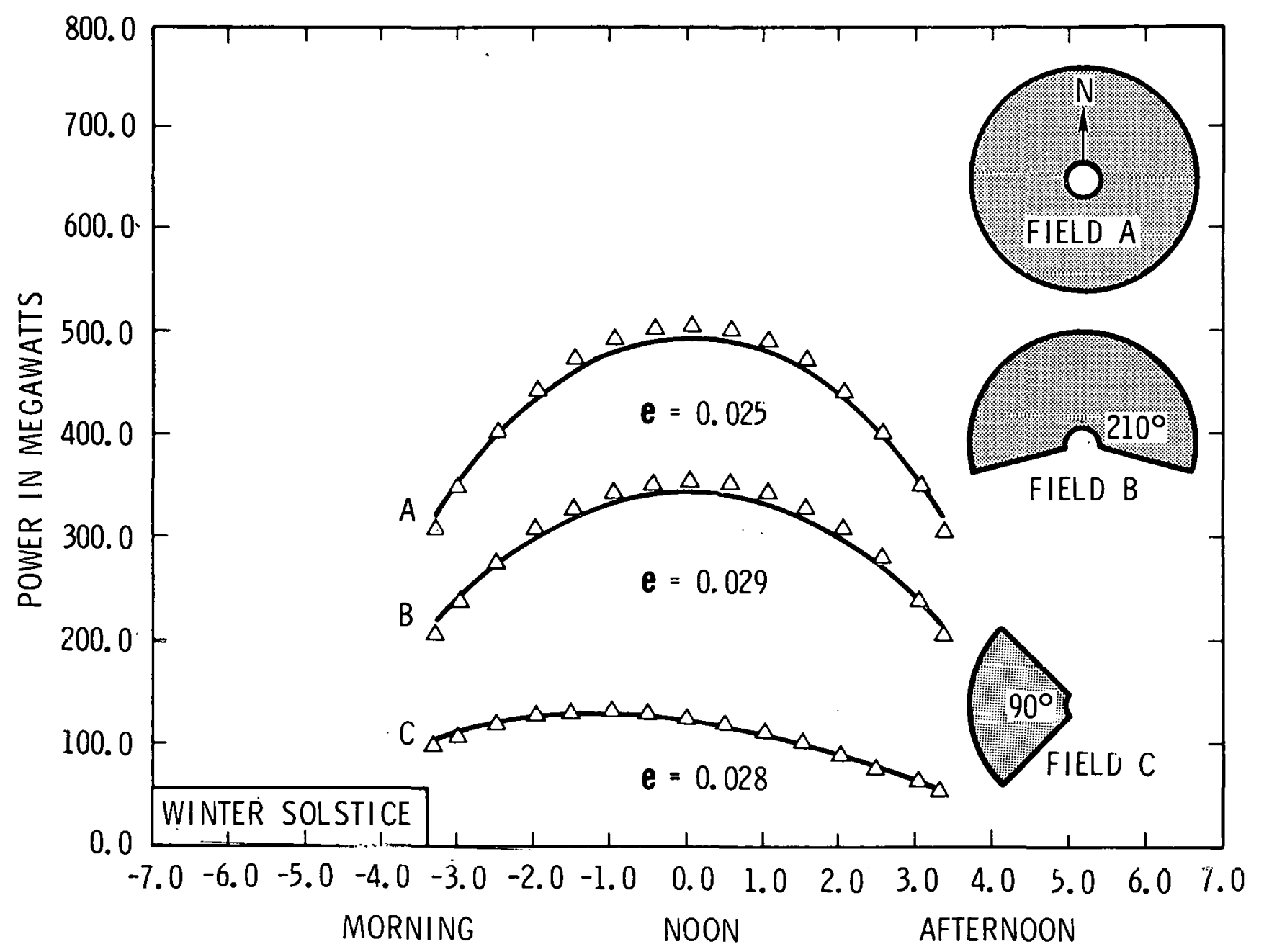

Figure 5. Power delivered to receiver area on December 22 (clear day) for three different field configurations. In all three fields the inner and outer radii are .75 and 7.5 tower heights, and the tower height is $87 \mathrm{~m}$. Latitude is $35^{\circ} \mathrm{N}$. The triangles are DELSOL results and the solid line is the SCRAM approximation. $\mathrm{e}$ is the rms error of the approximation, relative to the mean value. 


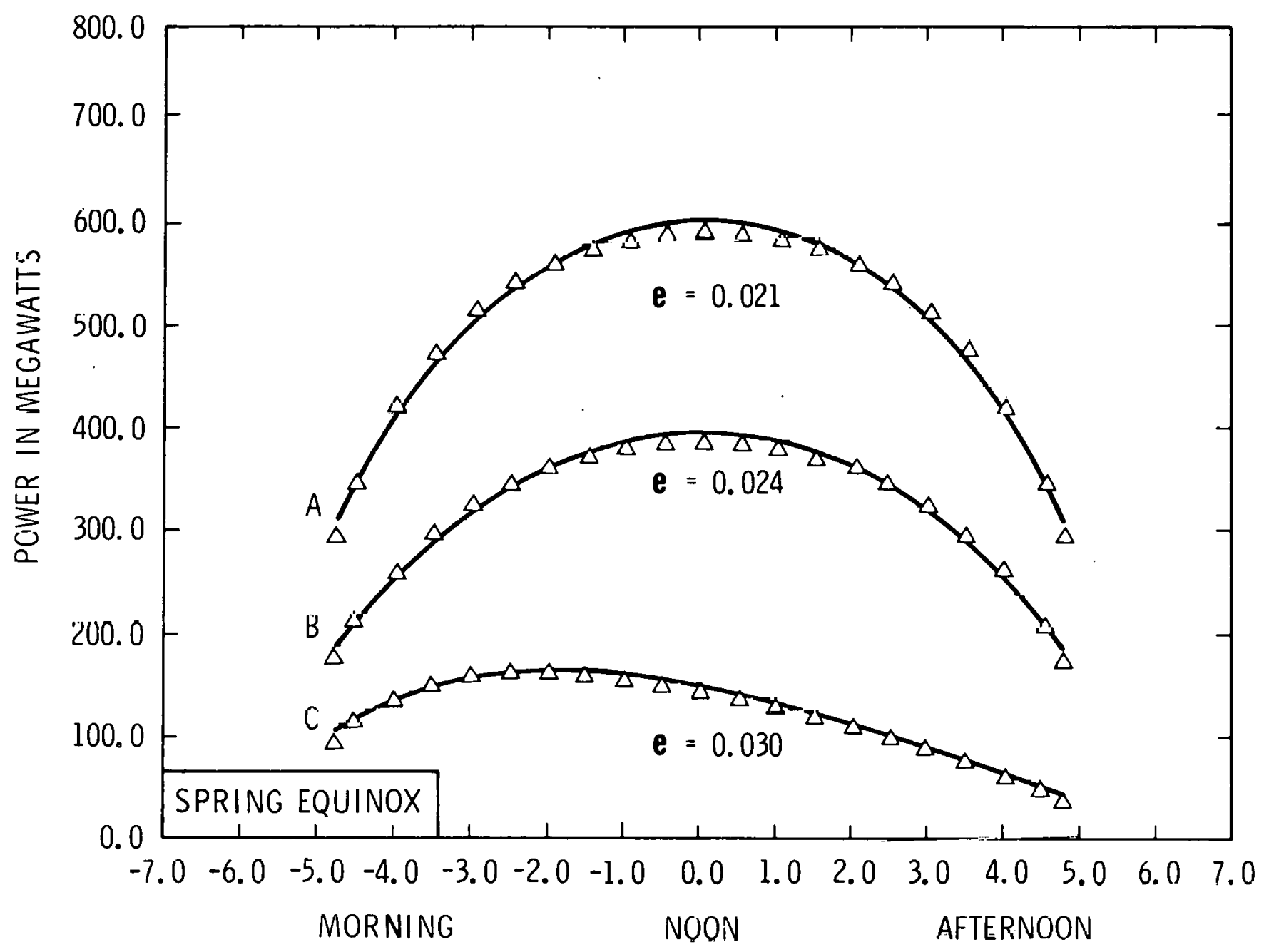

Figure 6. Same as Figure 5 but for March 21 . 


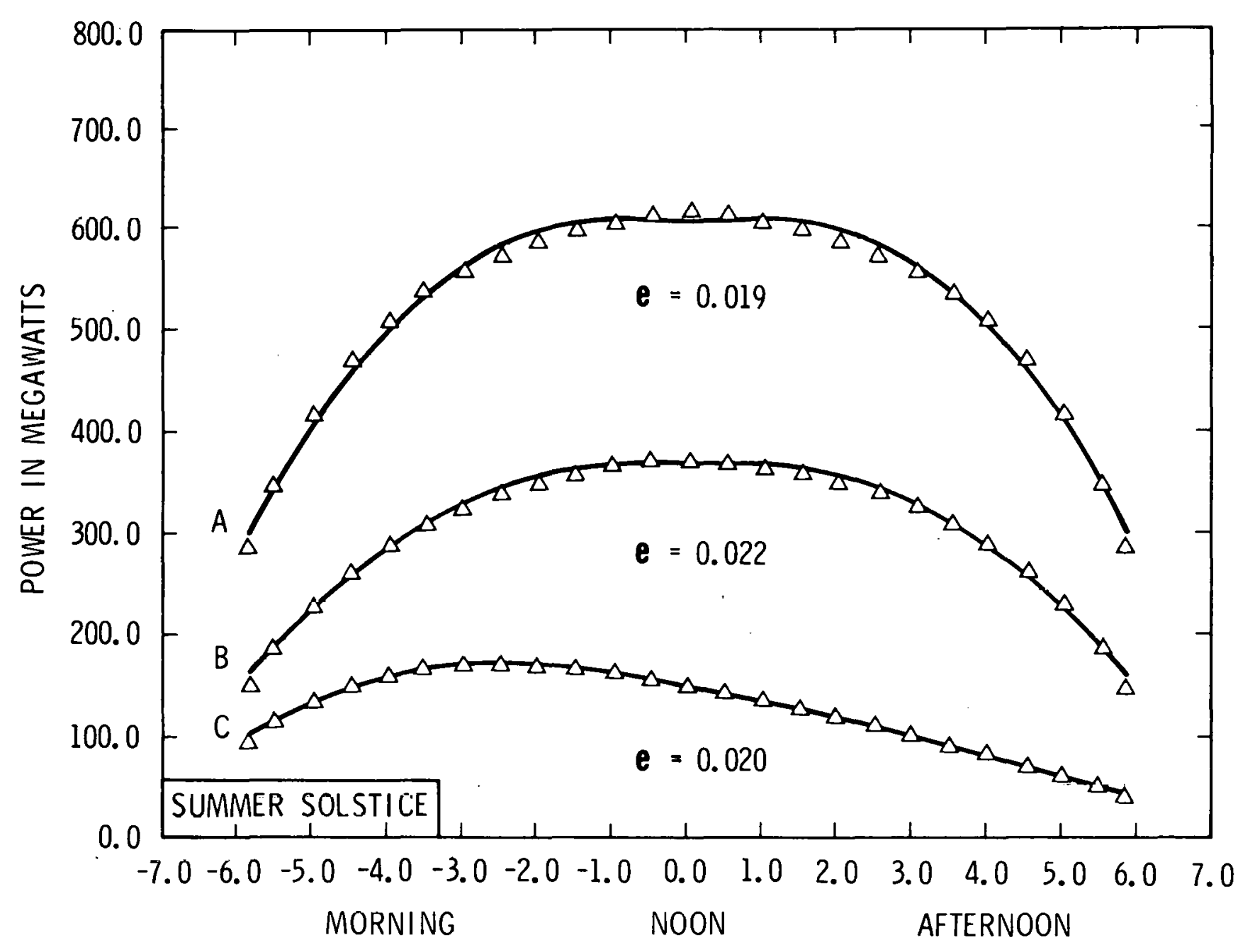

Figure 7. Same as Figure 5 but for June 22. 
As a more complete demonstration of the capabilities of the SCRAM code, we have calculated the daily performance of a particular heliostat field using TMY weather data for Albuque rque, NM, and the program outlined in Figure 4. The field layout and results are shown in Figure 8 . Total mirror area was $75,000 \mathrm{~m}^{2}$, and the tower height (calculated by the program) was $62.5 \mathrm{~m}$. The annual average efficiency for the field (defined by the dashed line in Figure 7 ) was $52 \%$. If receiver losses are not included, this number becomes $65 \%$.

This calculation required several thousand calls to the SCRAM subroutine (once every daylight hour for one year), and took 9.3 seconds of CDC 6600 computer time. Though it is difficult to make direct comparisons, this is $1,000-3,000$ faster than DELSOL, which in turn is probab1y faster than other existing PFCR codes. ${ }^{9}$ (It should also be noted that most of this 9.3 seconds is occupied by reading the weather data; only 3 seconds were actually used by the simulation programs.)

\section{Conclusion}

The fast computer model described here is not intended lo replace the large simulation codes for all applications. By increasing the speed of Llie calculation, we have limited the flexibility of the analysis as well. For example, we cannot change the geometry of the heliostats without generating a new data base. (See Appendix A for a discussion of which parameters can be changed and which cannot.)

However, the speed of the SCRAM model makes certain types of analysis possible which would require prohibitive amounts of time with the simulation codes. For example, optimizing the tower location on a fixed piece of land based on annual performance with realistic weather data would require more than $10^{5}$ evaluations of field performance, feasible for SCRAM, but not for any other existing code. Another suitable application would be the mutual optimization of field boundaries and storage size when a realistic load is considered and the effects of transients and local weather are treated. 


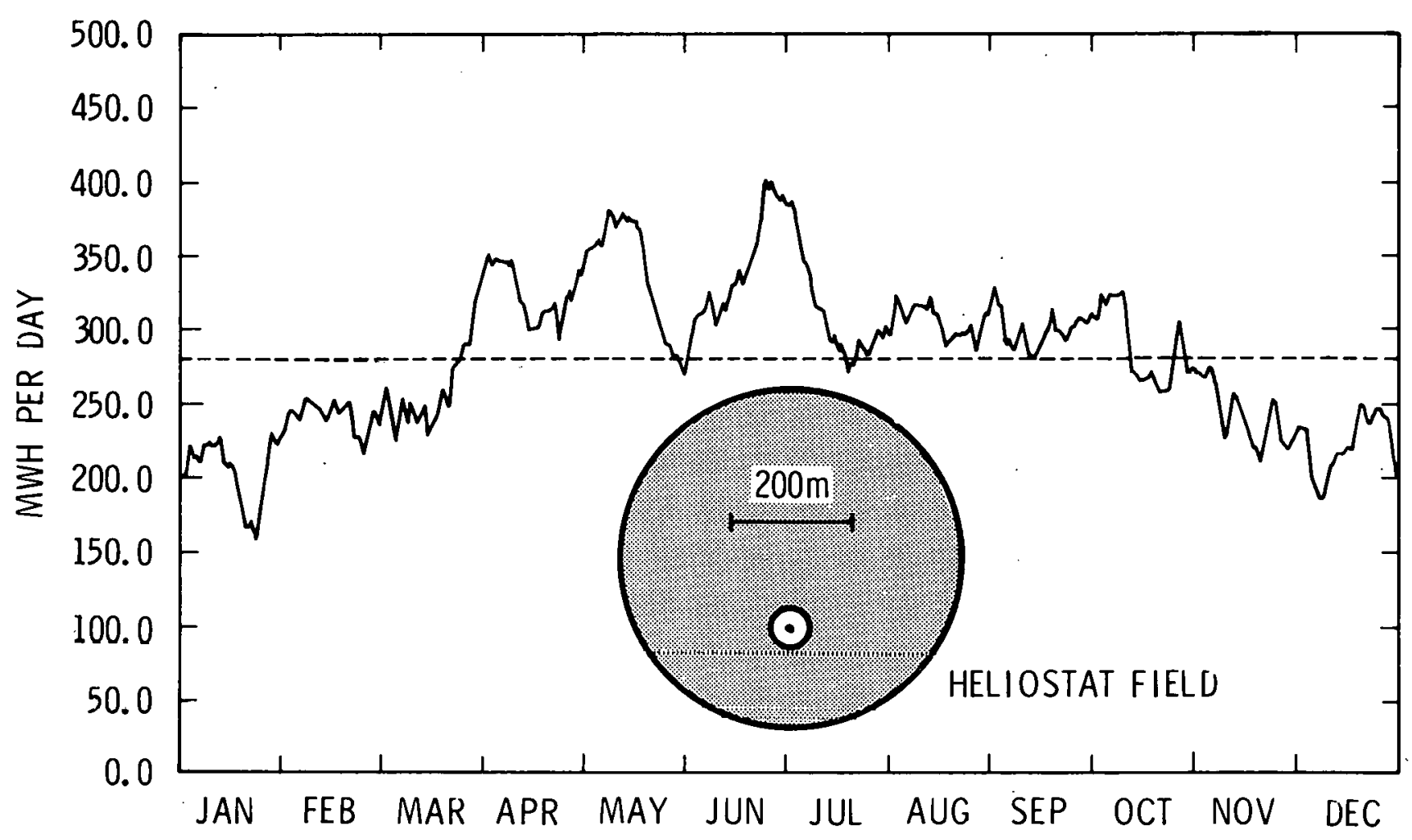

Figure 8. Annual performance of a PFCR system based on TMY (Typical Meteorological Year) data for Albuquerque, ${ }^{N M}$. Receiver losses are included. The mirror area is $75,000 \mathrm{~m}^{2}$ and the tower height (calculated by the program) is $62.5 \mathrm{~m}$. 
Another advantage is the simplicity of the computation. Since there is no need for a great deal of memory or speed, the model can be implemented on any size computer. Another possibility is that, once the field has been specified and the values of $x_{i j}$ have been determined by numerical integration, the calculation of field response can be performed on an even smaller machine (e.g., microcomputer or calculator), since only multiplication and addition is required. As central receiver systems evolve in stages from concept to prototype to potentially significant penetration of the electrical generation and industrial process heat markets, we can expect the importance of these and many other applications of a fast computer model to increase. 


\section{References}

1. F. Biggs and C. N. Vittitoe, "The Helios Model for the Optical Behavior of Reflecting Solar Concentrators," SAND76-0347, Sandia Laboratories, Albuquerque, NM.

2. P. Leary and J. Hankins, "A User's Guide for MIRVAL," SAND77-8280, Sandia Laboratories, Albuquerque, NM.

3. T. A. Dellin and M. J. Fish, "A Users Manual for DELSOL," SAND79-8215, Sandia Laboratories, Albuquerque, NM.

4. D. Siebers, "Natural Convection Heat Transfer From an External Receiver," SAND78-8276, Sandia Laboratorles, Albuquerque, NM.

5. R. L. Iman "STEPWISE Regression," SAND76-0364, Sandia Laboratories, Albuquerque, NM.

6. This was pointed out by $T$. Dellin, personal communication.

7. I. J. Hall, et a1. "Generation of Typical Meteorological Years for 26 SOLMET Stations," SAND78-1601, Sandia Laboratories, Albuque rque, NM.

8. J. M. Freese, "Effects of Outdoor Exposure on the Solar Reflectance Properties of Silvered Glass Mirrors," SAND78-1649, Sandia Laboratories, Albuquerque, NM.

9. The code documented in J. B. Woodard, G. J. Miller "STEAEC--Solar Thermal Electrical Annual Electric Calculator Documentation," SAND77-8278, Sandia Laboratories, Albuque rque, NM, is faster than DELSOL, and similar in some respects to SCRAM, but since it is restricted to a particular field design it is not considered relevant to this comparison.

10. F. W. Lipps and L. L. Vant-Hu11, Solar Energy 20, 505 (1978).

11. C. N. Vittitoe and F. Biggs, "Terrestrial Propagation Loss," SAND78-1137C, Sandia Laboratorles, Albuquerque, NM. 
APPENDIX A

Heliostat Characteristics and Scaling Relationships 
DELSOL requires a large number of input parameters to specify the geometry and characteristics of the heliostats. The values for the data which generated the SCRAM model presented in Table III are the default values defined in SAND79-8215 (Reference 3 ). The basic configuration is: a rectangular structure $7.4 \mathrm{~m} \times 7.4 \mathrm{~m}$ with focused, canted mirrors covering $90 \%$ of this area. The tower height is defined to be the distance from the horizontal rotation axis so that the height of the heliostat above the ground is not needed. Mirror reflectivity is .89 .

The field layout is basically a radial stagger pattern, also described in Reference 3. The heliostat density (mirror area/land area) as a function of field position is given by

$$
\rho=\frac{D_{M} \cdot(7.4)^{2}}{\Delta R \Delta A / 2}
$$

where $\mathrm{D}_{M}$ is the ratio of mirror area to heliostat area, and $\Delta R$ and $\Delta A$ are the radial and azimuthal separations (in meters) respectively. These separations are given by the formulas

$$
\begin{aligned}
\Delta \mathrm{R} & =\left(1.144 \cot \Theta_{\mathrm{L}}-1.094+3.068 \theta_{\mathrm{L}}-1.1256 \theta_{\mathrm{L}}^{2}\right) \cdot 7.4 \\
\Delta \mathrm{A} & =\left(1.749+0.6396 \theta_{\mathrm{L}}+\frac{0.02873}{\Theta_{L}-0.04902}\right) \cdot 7.4
\end{aligned}
$$

where $\theta_{L}=\cot ^{-1}(r)$ with $r$ in tower heights. These formulas are based on studies of optimum heliostat layout by workers at University of Houston. ${ }^{10}$ They are incorporated into the subroutine DENS in Appendix C.

The formula used for atmospheric attenuation is Eq. III. E-1 from Reference 3 corresponding to a clear day in Barstow, California. This formula, and others which could be substituted for different conditions and different locations can be found in Reference 11.

Most of the parameters characterizing the heliostats and layout are not variable once the SCRAM model, $C_{i j k}$, has been calculated. However, there 
are a few of them which can be varied without requiring a new model calculation because of the existence of simple scaling relations. Below are listed the parameters in question and the procedure required to take advantage of the scaling relation.

(1) Tower height: incorporated in existing algorithm (see Appendix D).

(2) Mirror reflectivity: multiply each $C_{i j k}$ by $\left(M_{r} / .89\right)$ where $M_{r}$ is mirror reflectivity.

(3) Different atmospheric attenuation mode1s: $C_{1 j k}$ unchanged; subroutine DENS is modified.

(4) $D_{M}$, ratio of mirror area to heliostat area: $C_{i j k}$ unchanged; parameter DENSMIR $=D_{M}$ in subroutine DENS is shanged from $n_{M}=.897$.

(5) Receiver losses (spillage, reflection, radiation, convection and conduction): incorporate into separate receiver model instead of the simplistic one used in SCRAM. (See Appendix C.) 
APPENDIX B

Generation of Field Mode1 
We begin with Eq. (7) for the local field efficiency:

$$
n_{p}=(r, \xi, \theta)=\sum_{i, j, k=1,4} c_{i j k} v_{i}(\theta) U_{j}(\xi) w_{k}(r)
$$

Integrating this over the field area as in Eq. (6) gives

$$
c_{f}(\theta, \phi)=\sum_{i, k=1,4} \int d \beta \int r d r W_{k}(r) v_{i}(\theta) \eta_{i k}(\phi, \beta)
$$

where we have introduced

$$
\begin{aligned}
\eta_{i k}(\phi, \beta) & =\sum_{j=1,4} c_{i j k}\{\cos ((j-1) \phi) \cdot \cos ((j-1) \beta) \\
& +\sin ((j-1) \phi) \sin ((j-1) \beta)\} .
\end{aligned}
$$

The definitions in Table II and the trigonometric expansion for $\cos (\phi-\beta)$ have been used to obtain Eq. (B3). We now restrict the field boundaries to two closed curves--an inner radius $r_{1}(\beta)$ and an outer radius $r_{2}(\beta)$ so that we can define $x_{i j}$ as follows:

$$
\begin{gathered}
x_{i 1}=\int_{r_{1}}^{r d r} \sum_{k=1,4}^{r_{2}} r W_{k}(r) c_{i l k} \\
x_{i j+1}=\int d B \sum_{k=1,4} \int_{x_{1 j+4}}^{r_{1}} r_{k}(r) d r C_{i j+1 k} \cos (j \beta) \\
\sum_{k=1,4}^{r_{2}} \int_{r_{1}}^{r_{2}} r_{k}(r) d r c_{i j+l k} \sin (j \beta)
\end{gathered}
$$


where $j=1,2,3$ in the last two equations. This allows us to write (B2) in the form

$$
c_{f}(\theta, \phi)=\sum_{\substack{i=1,4 \\ j=1, i}} x_{i j} v_{i}(\theta) u_{j}(\phi)
$$

which is Eq. (8) from the text. Since $x_{i j}$ does not depend on $\theta$ or $\phi$, it needs to be calculated only once for each field. 
APPENDIX C

Optional Receiver Mode1 


\section{1 Thermal and Reflection Losses}

As discussed in the text, the principal reason for separating field losses from receiver losses in this analysis is that the nature of the physics and the accuracy of existing calculational tools for the processes involved is significantly different for the two categories. For example, the best current models for calculating convective heat loss are not nearly as well developed as our ability to do classical optics calculations. (However, it is to be expected that in the next few years rapid progress in understanding the thermal properties of PFCR systems will result from the DOE research and demonstration program.)

In this section, a simplified model for receiver performance is described, partly as a demonstration of how such a model would be incorporated and partly to provide a more complete PFCR simulation for applications which do not require high levels of accuracy for receiver performance.

We have identified receiver losses as consisting of five terms, as indicated in Table $I$. In our receiver model, the loss due to reflection is treated simply by assigning a value to $n_{7}$, identified as ROPT in SCRAM. This is suitable for both external and cavity receivers, though for the latter it is the effectlve absorptivity of the cavity (before re-radiation) which is being modeled.

The three thermal terms, $n_{8}, n_{9}$, and $n_{10}$, are also dealt with in a very simple manner. It is assumed that the receiver is held at a fixed temperature regardless of insulation level (by controlling the flow of heat transfer fluid) so that the power loss is simply a constant in time. The quantity RTHER in subroutine SCRAM specifies this loss in units of power consistent with the insolation units. No attempt has been made to model the dependence of this quantity on temperature, wind speed, etc. Thus the receiver model for the terms $n_{7} n_{8} n_{9} n_{10}$ is:

$$
\text { Collected Power }=\text { Incident } \text { Power }^{\bullet} \text { ROPT }- \text { RTHER }
$$

For the example of Figure 8 , the quantities RTHER $=2 . \mathrm{MW}$ and ROPT $=.87$ were used. The former was based on an arbitrary assumption of a thermal 
loss equal to $5 \%$ of the peak collected power, while the latter is a rather conservative estimate of absorptivity for an external receiver.

\section{2 Spillage}

It is natural to treat $n_{7-10}$ as attributes of the receiver, but it is somewhat arbitrary to consider $\eta_{6}$, the spillage term, a property of the receiver. It is actually a property of the interface between the field and the receiver, and as such it presents some problems for a fast approximation procedure.

Strictly speaking, spillage is an optical process and DELSOL's treatment of it should have the same high level of accuracy as the other optical terms in the field efficiency. However, there are important advantages to including spillage in the receiver model and treating it in an approximate way.

Firstly, it should be noted that spillage depends on a large number of parameters, including receiver dimensions and heliostat errors, as well as $r, \theta$, and $\xi$. In fact, for a typical, simple system (external cylindrical receiver, canted and focused heliostats) DELSOL requires fifteen input parameters for the heliostats and three for the receiver. Of these eighteen parameters, fully fourteen affect only the spillage losses. Thus, if the polynomial $n_{p}$ does not include spillage, there is a substantial increase in the generality of the polynomial.

Secondly, spillage in a well-designed system typically makes a very small contribution to PFCR losses. The reason is that the heliostat field represents such a large proportion of system costs that it is cost-effective to design receivers which intercept almost all of the reflected light. For example, in a typical set of DELSOL-optimized PFCR systems, the annual spillage loss is less than $1 \%$.

On the other hand, we do not want to disregard spillage in certain types of problems (e.g. field boundary optimization). The procedure to be adopted here is based on the simple assumption of ignoring the dependence of spillage on $\theta$ and $\xi$ (which is known to be a weak dependence for 
typical systems). With spillage a function only of $r$, it can be treated in the same manner as $\eta_{5}$, atmospheric attenuation (included in the subroutine FLDSET).

The function used for our optional receiver model is based on DELSOL results using canted, focused heliostats and an external cylindrical receiver. As before, the parameters used are the default values of Reference 3 . The functional form is

$$
\begin{array}{ll}
n_{7}=1 & (r \leqslant 4.2) \\
n_{7}=1-(r-4.2)^{1.89} & (r>4.2)
\end{array}
$$

An analysis of DELSOL runs indicates that errors introduced by this approximate treatment would typically be less than $10 \%$ of the spillage, hence less than $.1 \%$ of the energy collected.

One important advantage of this procedure is a substantial increase in flexibility. Thus, a different recelver geometry or different heliostat characteristics would require a new spillage function, but not a new field polynomial. Furthermore, the spillage calculation only requires the analysis of a single heliostat located at varying values of $r$ (and preferably at $\left.\xi=90^{\circ}\right)$.

If single-cavity receivers or receivers whose parameters are very far from optimum are used, this treatment of spillage may not be adequate. For example, a south-facing cavity will obviously not accept light from the north part of the field. It might then be possible to introduce an angledependent spillage factor (which would be included in FLDSET). Similarly, receiver design and performance studies will probably require flux maps on the receiver surface and the SCRAM approach would be unsuitable. However, for most system studies and field design studies involving receivers designed for surround fields, the treatment of spillage outlined above should be entirely adequate. 
APPENDIX D

Computer Subroutines for Implementing the SCRAM Model 
The following subroutines were used with different executive programs to generate the data for Figures 5-8. The flow chart for the program generating Fig. 8 is shown in Fig 4. Two library subroutines for numerical quadrature were used: QNC3 for function-generated integrands, and AVINT for integrating discrete data sets. They should be replaced by appropriate substitutes for systems other than that at Sandia Laboratories.

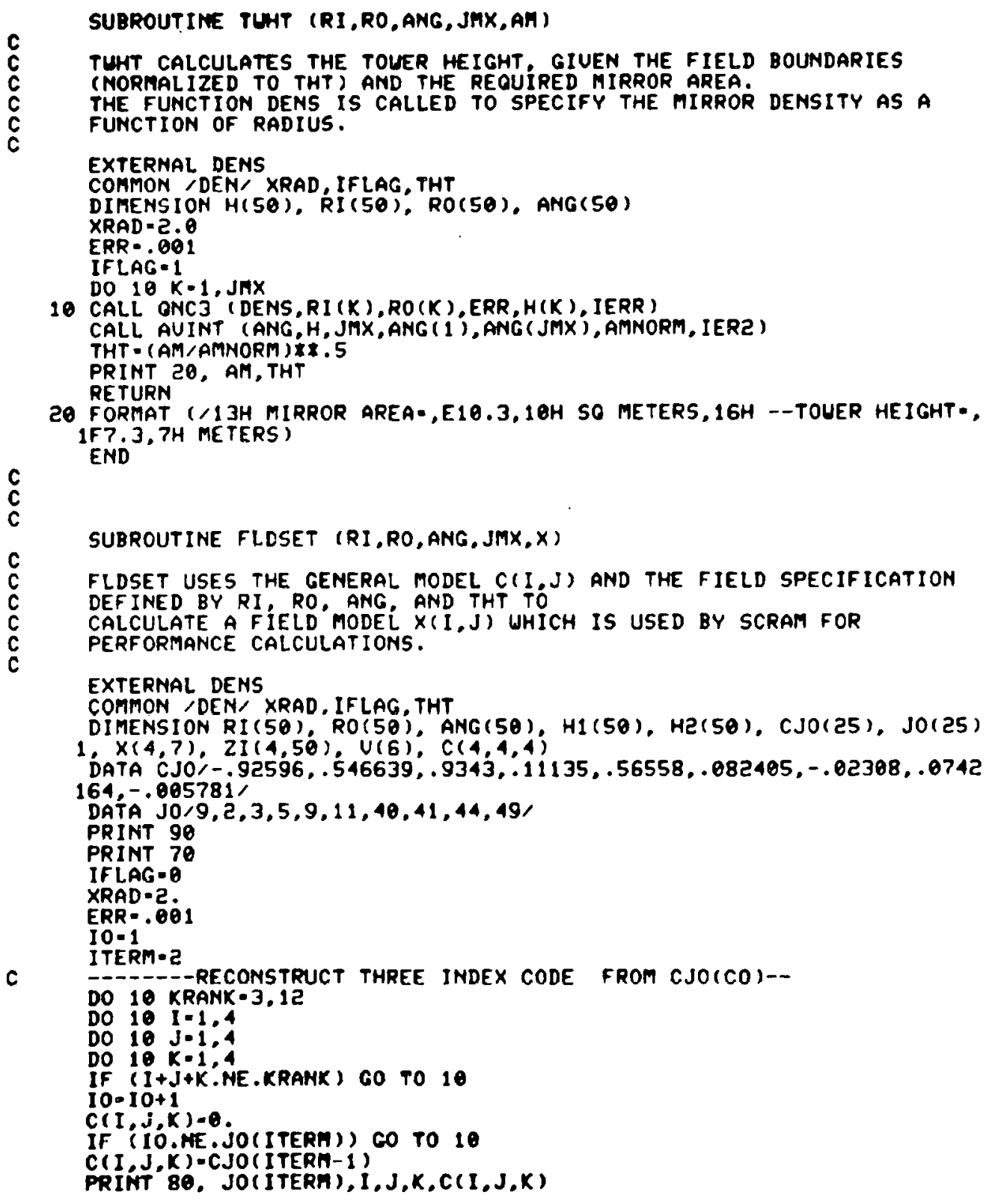


ITERA-ITERA+1

10 CONTINUE

-----PERFORA R INTEGRALS--.--

DO $30 K-1,4$

DO $20 K K \cdot 1, \operatorname{JnX}$

XRAD -K

CALL ONC3 (DENS,RI (KK),RO (KK),ERR, ANS, IERR)

$202 I(K, K K)=A N S$

30 CONTINUE

DO $6 \theta \mathrm{B}-1.4$

DO $60 \mathrm{~J}=1.4$

$X(I, J)=0$.

$2 J-j-1$

DO $50 \mathrm{KK} \cdot 1, \mathrm{JMX}$

$\mathrm{DH}=0$ :

DO $40 \quad K=1,4$

$40 D H=D H+C(I, J, K) \times Z I(K, K K)$

$H 1(K K)-D H \times \operatorname{COS}(2 J \times A N G(K K))$

$50 \mathrm{HZ}(K K)=D H * S \operatorname{IN}(2 J \times A N G(K K))$

CALL AUINT (ANG,H1,JMX, ANG (1), ANG (JMX),PO1, IER1)

CALL AUINT (ANG, HE, JMX, ANG (1), ANG (JMX),POZ, IERZ)

X(I.,I)-POIXTHTIX:C

60 IF $(J . N E .1) \times(I, J+3)=P 02 * T H T * 2 Z$

KE I UKN

C

70 FORMAT (124H JO I J $K$ CO/)

80 FORMAT (4I4,E14.7)

90 FORMAT (/2ZH SCRAM MODEL C $(I, J, K) ! /)$

END

$c$
$c$
$c$

SUBROUTINE SCRAM (SAA, SPA, AM, DM,PUR, $X$ )

$c$
C
$c$
C
C
C

SCRAM USES THE FIELD MODEL $X(I, J)$ TO CALCULATE THE ENERGY

INCIDENT ON THE RECEIUER. IT CAN ALSO (IF IREC=1)

CALCULATE POUER LOST AT THE RECEIUER AMD RETURNS NET POWER

COLLECTED TO ANYFLD.

COMMON /REC/ ROPT,RTHER, IREC

DIMENSION E(4), $X(4,7)$

E(1)-1.

$E(2)=\cos (S P A)$

E( 3 )-SIA(SPA)

$E(4)-E(3) \times E(2)$

ETA-O.

Do $30 I-1.4$

$E F \cdot x(1,1)$

UU CU JE1, J

$\mathbf{F} \mathbf{J}-\mathbf{J}$

IF $(x(I, J+1), E 0.0$.$) CO TO 10$

$E F=x(1, j+1) \times \cos (F j \times S A A)+E F$

10 If $(x(1, j+4), E 0,0)$.60 TO 20

$E F-E F+X(1, J+4) \notin S I N(F J \$ S A A)$

Pด CINNTINIIF

39 ETA-ETA+EF $\$ E(I)$

C

PUR-ETAXDN

- - OPTIONAL RECEIUER MODEL--- 


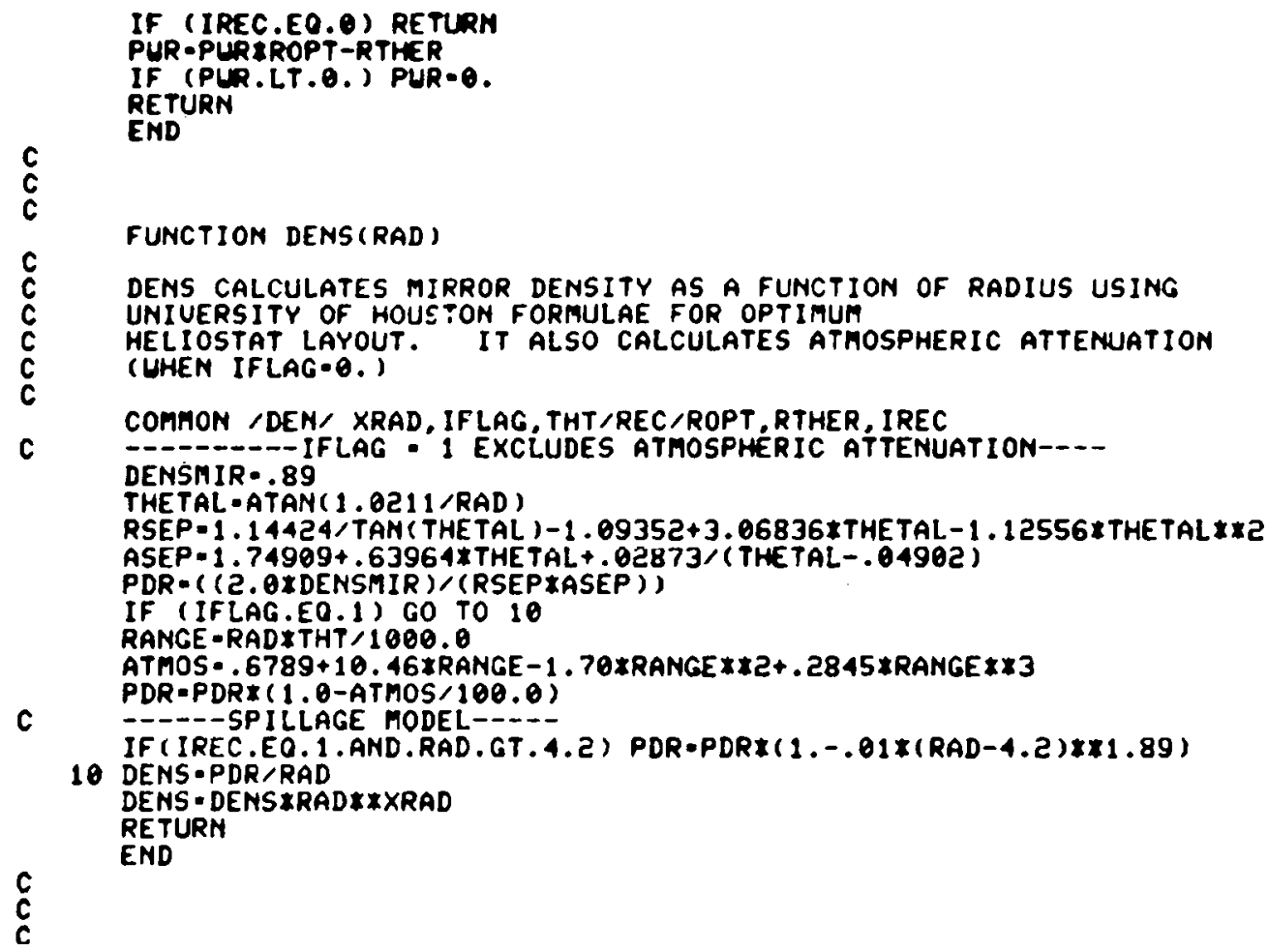

$\mathbf{C}$
$\mathbf{C}$
$\mathbf{C}$ 
Distribution:

TID4500-R67-UC62 (263)

Douglas Aeronautics Co. 5310 Bolsa

Huntington Beach, CA 92647

Attn: J. Raetz

4231 J. H. Renkin

4231 F. Biggs

4231 C. N. Vittitoe

4700 J. H. Scott.

4710 G. E. Brand vold

Solar Energy Research Institute (5)

4713

4720

B. W. Marshall

1536 Cole Blvd.

Golden, Co 80401

4721

V. L. Dugan

Attn: F. Kreith

4722

J. V. Otts

N. Woodley

4723

J. F. Banas

J. Thornton

4723

W. P. Schimmel, Jr. (5)

C. Bishop

K. D. Bergeron (50)

M. Cotton

4723

T. A. Dellin

4725 J. A. Leonard

8000 T. B. Cook

General Electric ESPD

Schenectady, NY 12345

Attn: A. N. Blackwe11

Attn: S. Schwartz

8320

8326

8450

Westinghouse Advanced Energy Systems

8451

R. Rinne

M. J. Fish

Division

PO Box 10864

Pittsburgh, PA 15236

Attn: H. H. Lipner

University of Houston (2)

Solar Energy Laboratory

4800 Calhoun

8451 T. D. Brumleve

8451 H. Norris

8452 A. C. Skinrood

8452 C. Hackett

8266 E. A. Aas

3141 T. L. Werner (5)

$315 \mathrm{I}$ W. L. Garner (3)

Houston, TX 77004

For DOE/TIC (Unlimited Releasc)

Attn: F. Lipps

L. Vant-Hul1

Martin-Marietta

PO Box 179

Denver, CO 80201

Attn: J. Montague, MS-S0403

Boeing Engineering and Construction PO Box 3707

Seatlle, WA 98124

Attn: J. Gintz

US Department of Energy (4)

Division of Central Solar Technology

Washington, DC 20545

Attn: G. Braun

G. Kaplan

J. Rannels

W. Aue $r$ 


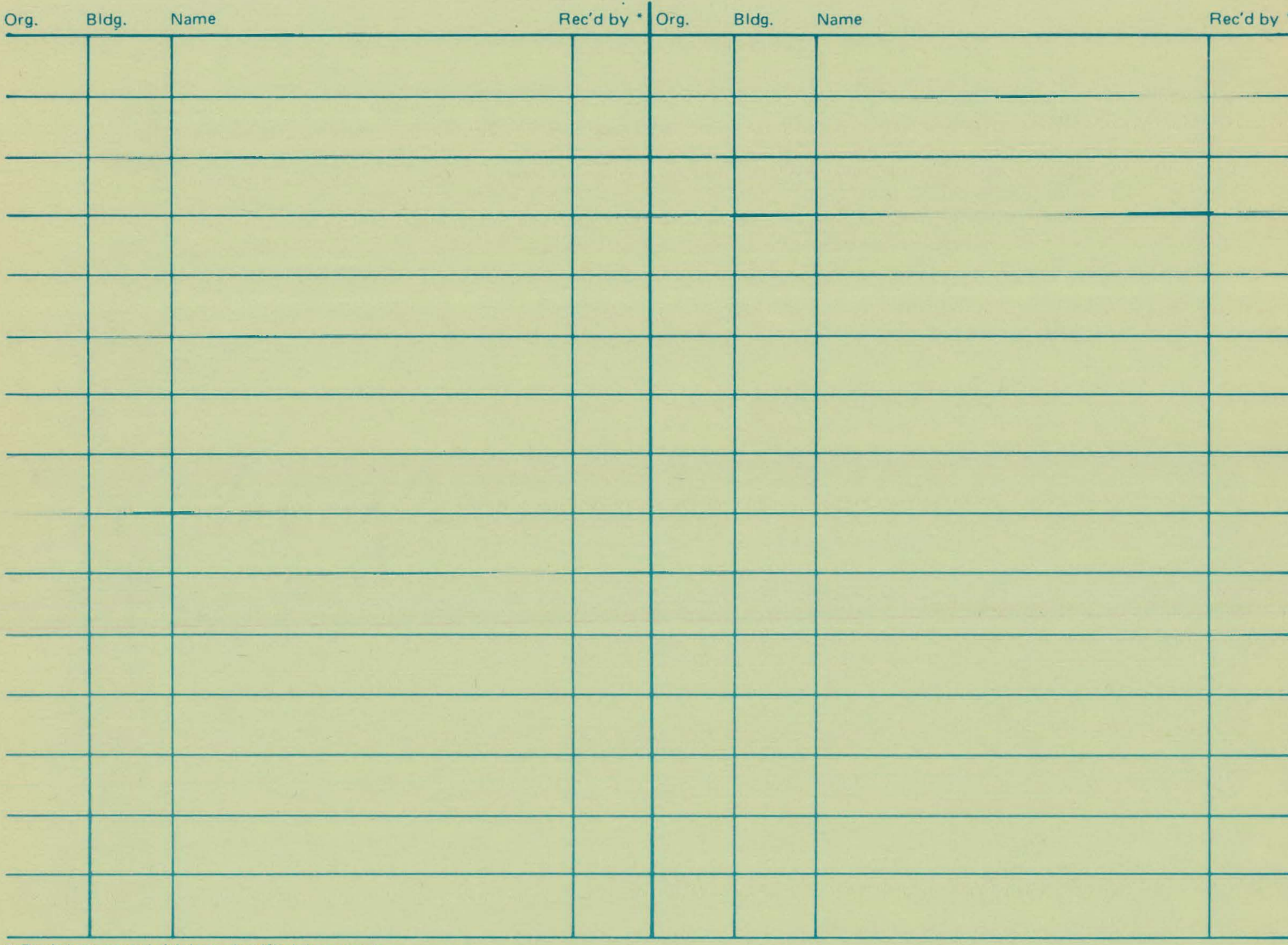

- Recipient must initial on classified documents. 